Research Article

Journal of Extension Education

Vol. 30 No. 1, 2018

DOI:https://doi.org/10.26725/JEE.2018.1.30.6019-6024

\title{
Perception of Farmers about a Pilot Extension Project (LEADS) in two Districts of Kerala
}

\author{
Preethu K. Paul ${ }^{1}$, G. S. Sreedaya ${ }^{2}$ and Dhanusha D Balakrishnan ${ }^{3}$
}

\begin{abstract}
Lead Farmer Centered Extension Advisory and Delivery Services (LEADS) is a pilot extension system revolving around Lead farmer - Satellite farmer concept on an Agro Ecological Zone basis within a district. The present study was conducted in the Kollam and Palakkad districts of Kerala state to compare the perception level of the farmers towards LEADS regarding the effectiveness in implementation of LEADS of both districts. From the study conducted, it was clear that the perception of farmers was found to be more in Kollam than in Palakkad district in terms of effectiveness of the extension system.
\end{abstract}

Keywords : Pilot extension project; LEADS; Perception; Perception Index; lead farmers; satellite farmers; Kerala

\section{INTRODUCTION}

Kerala, a premier state in India with a tradition of many innovative social development programmes has implemented many novel projects across the state in the past sixty years, which aimed at developing the state's agriculture. There was a noticeable gap in the provision of agricultural extension services to the farmers. With many peculiarities in the agricultural sector of Kerala, the gap in agricultural extension was particularly disadvantageous to the small and marginal farmers. While one could observe some farmers reaping record yields, majority of the other farmers had to grapple with poor yields and this led to reduced returns making the agricultural system, an unviable economic activity. Many of the developmental programmes pin pointed shortfalls like lack of farmer to farmer extension and lack of periodic field visits. This thought has led to the implementation of the LEADS pilot project by the Kerala State Planning board (Sreedaya, 2016). LEADS is Lead Farmer Centered Extension Advisory and Delivery Services which is a pilot extension system revolving around Lead farmer - Satellite farmer concept on an Agro Ecological Zone basis within a district. Lead farmer concept follows the Farmer to farmer (F2F) extension approach. $\mathrm{F} 2 \mathrm{~F}$ extension system is a cost-effective and potentially sustainable service delivery mechanism to rural farmers. Lead farmers are those farmers who possess high amount of innovativeness and satellite farmers are the

$1 \& 3$ Assistant Professor (contract) and 2 Assistant Professor, Department of Agricultural Extension, College of Agriculture Vellayani, Kerala Agricultural University- Thrissur, Kerala, India

Received : 26-03-2018; Accepted : 02-05-2018 
farmers who revolve around the lead farmers and adopt the technologies recommended by the lead farmers. The performance of the agricultural development projects always possesses a cumulative effect in attaining the objectives and even well conceived agricultural development programmes in the past years have suffered from many implementation problems. Impact assessment of the projects are essential to ascertain the success of any project.

The present study was proposed to compare the perception of farmers regarding the effectiveness in implementation of LEADS in Kollam and Palakkad districts.

\section{METHODOLOGY}

The study was conducted in five developmental blocks of Kollam district and 5 blocks of Palakkad district of Kerala. Fifteen Lead farmers and 30 Satellite farmers were selected from both the districts as respondents. Comparison of perception of farmers regarding the effectiveness in implementation of LEADS in Kollam and Palakkad districts was done by modifying the scale developed by (Preethi et al.,) 2014.The statements were scored by using the perception index.

\section{FINDINGS AND DISCUSSION}

Perception is the process by which an individual becomes aware of the objects around him and of the events that takes place. Results of the study are categorized into the perception of lead farmers and perception of the satellite farmers.
Perception of the Lead farmers regarding the Effectiveness in Implementation of LEADS

The respondents were categorized into three groups, viz., low, medium and high based on the quartile deviation. From the data, it is clear that majority of the Lead farmers of Kollam and Palakkad district possessed a

Table 1.

Distribution of Lead farmers based on their Perception regarding the Effectiveness in Implementation of LEADS.

\begin{tabular}{|c|l|c|c|c|}
\hline Sl. & \multicolumn{2}{|c|}{ KOLLAM } & \multicolumn{2}{c|}{ PALAKKAD } \\
\cline { 2 - 5 } No. & \multicolumn{1}{|c|}{ Category } & Percentage & Category & Percentage \\
\hline 1. & $<88$ (low) & 6.67 & $<76$ (low) & 3.33 \\
\hline 2. & $88-97$ (medium) & 80 & $76-80$ (medium) & 73.33 \\
\hline 3. & $>97$ (high) & 13.33 & $>80$ (high & 20 \\
\hline 4. & Total & 100 & Total & 100 \\
\hline 5. & Q1 - 88 Q3- 97 & Q1 - 76 & Q3 - 80 \\
\hline
\end{tabular}


medium level of perception i.e. 80 per cent and 73.33 per cent respectively regarding the effectiveness in implementation of LEADS. On comparing the perception of Lead farmers of both the districts, perception regarding the effectiveness in implementation of LEADS was found higher for the Lead farmers of Kollam district than that of Palakkad district (Table 1).
Based on the perception, perception index of lead farmers for the statements was assessed, and the results are depicted in Table 2.

The perception scale selected consisted of eight statements measured in a five-point continuum, viz., strongly agree, agree, undecided, disagree and strongly disagree.

Table 2.

Perception Index (PI) of Lead farmers of Kollam and Palakkad Districts

\begin{tabular}{|c|l|c|c|}
\hline SI. No & \multicolumn{1}{|c|}{ Statements } & Kollam-PI & Palakkad - PI \\
\hline 1 & $\begin{array}{l}\text { LEADS methods are more effective than } \\
\text { conventional methods }\end{array}$ & 93.33 & 73.33 \\
\hline 2 & $\begin{array}{l}\text { LEADS helps farmers to access new } \\
\text { technologies and products easily }\end{array}$ & 73.33 & 66.66 \\
\hline 3 & $\begin{array}{l}\text { Group approach of LEADS is more effective } \\
\text { than individual approach }\end{array}$ & 86.66 & 53.33 \\
\hline 4 & $\begin{array}{l}\text { Participative decision making is ensured in } \\
\text { the implementation of LEADS methods }\end{array}$ & 80 & 73.33 \\
\hline 5 & $\begin{array}{l}\text { Farmers get an opportunity to take } \\
\text { leadership in technology dissemination } \\
\text { process }\end{array}$ & 53.33 & 60 \\
\hline 6 & $\begin{array}{l}\text { Greater economic prosperity can be achieved } \\
\text { through LEADS }\end{array}$ & 80 & 73.33 \\
\hline 7 & $\begin{array}{l}\text { Participative skill training helps farmers to } \\
\text { adopt new technologies and methods }\end{array}$ & 60 & 80 \\
\hline 8 & $\begin{array}{l}\text { Farmers get an opportunity to introduce their } \\
\text { own innovations to the farming community }\end{array}$ & 73.33 & \\
\hline
\end{tabular}

From the Perception index, it is clear that in Kollam district, statements such as 'LEADS methods are more effective than conventional methods' and 'group approach of LEADS was more effective than individual approach' were having a perception score of 93.33 and 
86.66 respectively and in Palakkad district the statements viz., 'LEADS helps farmers to access new technologies and products easily' and 'farmers get an opportunity to introduce their own innovations to the farming community' were having a perception score of 86.66 and 80 respectively.

In Kollam district, LEADS was being implemented under the supervision of expert extension officials and clearly proved the results. Whereas in Palakkad district due to lack of supporting staff, farmers awareness was found to be less about the concept of LEADS. This might be the reason for the above findings.

Perception of the Satellite farmers regarding the Effectiveness in Implementation of LEADS
The distribution of the satellite farmers regarding the effectiveness in implementation of LEADS is shown in Table 3.

The respondents were categorized into three groups viz., low, medium and high based on the quartile deviation. From Table 3, it is clear that majority of the satellite farmers of Kollam and Palakkad district possessed a medium level of perception 63.33 percent and 43.33 percent respectively regarding the effectiveness in implementation of LEADS.

On comparing the perception of satellite farmers of both the districts, perception regarding the effectiveness in implementation of LEADS was found higher for the satellite farmers of Kollam district than that of Palakkad district.

Table 3.

Distribution of Satellite Farmers on Perception regarding the Effectiveness in Implementation of LEADS.

\begin{tabular}{|c|c|c|c|c|}
\hline \multirow{2}{*}{ SI. No } & \multicolumn{2}{|c|}{ Kollam } & \multicolumn{2}{c|}{ Palakkad } \\
\cline { 2 - 5 } & Category & Percentage & Category & Percentage \\
\hline 1 & $<73$ (low) & 13.33 & $<64$ (low) & 26.67 \\
\hline 2 & $73-84$ (medium) & 63.33 & $64-72$ (medium) & 43.33 \\
\hline 3 & $>84$ (high) & 23.33 & $>72$ (high & 30 \\
\hline 4 & Total & 100 & Total & 100 \\
\hline
\end{tabular}

Perception scale consisted of ten statements measured in a five-point continuum viz., strongly agree, agree, undecided, disagree and strongly disagree. Majority of the respondents of Kollam district strongly agreed with the perception statements such as 'LEADS methods are more effective than conventional methods' and 'group approach of LEADS is more effective than individual approach'. 
In Palakkad district majority of the respondents strongly agreed with the perception statements such as 'LEADS helps farmers to access new technologies and products easily' and 'farmers got anopportunity 4. to introduce their own innovations to the farming community'. Based on the perception, perception index of satellite farmers for the statements was assessed out using the formula, and the results are depicted in Table

Table 4.

Perception Index of Satellite Farmers of Kollam and Palakkad districts

\begin{tabular}{|c|c|c|c|}
\hline SI.No & Statements & Kollam-PI & Palakkad - PI \\
\hline 1 & $\begin{array}{l}\text { LEADS methods are more effective than } \\
\text { conventional methods }\end{array}$ & 96.66 & 93.33 \\
\hline 2 & $\begin{array}{l}\text { LEADS helps farmers to access new technologies } \\
\text { and products easily }\end{array}$ & 90 & 80 \\
\hline 3 & $\begin{array}{l}\text { Group approach of LEADS is more effective than } \\
\text { individual approach }\end{array}$ & 86.67 & 90 \\
\hline 4 & $\begin{array}{l}\text { Participative decision making is ensured in the } \\
\text { implementation of LEADS methods }\end{array}$ & 66.67 & 70 \\
\hline 5 & $\begin{array}{l}\text { Farmers get an opportunity to take leadership in } \\
\text { technology dissemination process }\end{array}$ & 73.33 & 86.67 \\
\hline 6 & $\begin{array}{l}\text { Greater economic prosperity can be achieved } \\
\text { through LEADS }\end{array}$ & 70 & 63.33 \\
\hline 7 & $\begin{array}{l}\text { Participative skill training helps farmers to adopt } \\
\text { new technologies and methods }\end{array}$ & 83.33 & 73.33 \\
\hline 8 & $\begin{array}{l}\text { Farmers get an opportunity to introduce their } \\
\text { own innovations to the farming community }\end{array}$ & 76.67 & 83.33 \\
\hline
\end{tabular}

\section{CONCLUSION}

A comparative analysis on the perception of farmers regarding the effectiveness in implementation of LEADS in Kollam and Palakkad showed that farmers of Kollam district possessed higher level of perception regarding the effectiveness in implementation of LEADS, when compared to the farmers of Palakkad district. The policy makers $\&$ extension professionals can take a cue from the results of the study and act accordingly. 


\section{REFERENCES}

Preethi, M., Nataraju, S., \& Lakshminarayan, M. T. (2014). Development of a scale to measure perception of farm youth towards agriculture. International Journal of Extension Education, 10, 165-167.
Sreedaya, G. S. (2016). A final report submitted to the Director, State department of Agriculture: Monitoring and Evaluation of Lead Farmer Centered Extension Advisory and Delivery services (LEADS)- pilot project in four districts of Kerala, Trivandrum. P.14. 